\title{
ELECTRON HISTOCHEMICAL EXAMINATION OF CYTOCHROME OXIDASE IN THE RETINAL PHOTORECEPTOR CELL OF COPPER DEFICIENT RATS
}

\author{
YOSHINORI DAKE \\ Department of Ophthalmology, Nagasaki University School of Medicine, Nagasaki 852 \\ Received for publication June 10, 1991 and in revised form October 23, 1991
}

\begin{abstract}
The activity of cytochrome oxidase in photoreceptor inner segments of copper deficient rats was investigated by the diaminobenzidine method with electron microscopy. The deposits of reactive products resulting from oxidation in the mitochondrial intermembrane-intracristal space were measured in the computed image analyzer. Copper deficient rats showed neurological disorders and significantly low levels of serum copper throughout the experiment. The light microscopic findings showed that stainability for cytochrome oxidase in the retinal photoreceptor inner segment was less in the copper deficient rats than in the control rats. Ultrastructurally, $\mathrm{DAB}-\mathrm{OsO}_{4}$ reaction products were diffusely located on the inner membranes and in the intracristal spaces of mitochondria in the control rats. Depositions of DAB in the copper deficient rats were insignificant and occupied a narrow area of the intracristal space, although the mitochondria showed no morphological changes. It was concluded that copper deficiency reduced cytochrome oxidase activity in the photoreceptor inner segments without morphological changes of the mitochondria.
\end{abstract}

Since Hart et al. (9) showed that trace metal copper is related to hemoglobin synthesis, the role of copper in biological synthesis of phospholipid has been well investigated in the cerebrum, cerebellum, liver and heart $(7,15,19)$. It was demonstrated that copper is an essential nutrient related to the enzymatic activities of metalloenzymes, such as cytochrome oxidase, superoxide dismutase and dopamine $\beta$-hydroxylase, in the development of the nervous and cardiovascular systems in the neonatal period $(14,21$, 22). Our previous study (12) demonstrated that trace metal copper was located in the cornea, iris, ciliary body, retina and pigment epithelial layer. However, its role in ocular tissues has not yet been fully examined. The purpose of this study was to examine the morphological changes and the level of cytochrome oxidase activities in the retinas of copper deficient rats.

Mailing address: Yoshinori Dake, M. D., Department of Ophthalmology, Nagasaki University School of Medicine, 7-1 Sakamoto-machi, Nagasaki 852, Japan.

\section{MATERIALS AND METHODS}

\section{Experimental diet}

Following the prescription of the American Institute of Nutrition (1), a copper deficient diet was prepared by Cler Japan, Inc, Tokyo. Its composition is shown in Tables 1 and 2.

\section{Experimental animals}

Mature female Wistar albino rats weighing $200 \mathrm{~g}$ were mated with males fed commercial rat pellets. After mating, all females were housed individually in plastic tubs until delivery and divided into copper deficient and control groups. During gestation and lactation, females were fed a purified diet low in copper and given deionized water. The control group was given the same purified diet plus supplemental copper in their drinking water as copper sulfate $(\mathrm{Cu}$ : $20 \mathrm{ppm}$ ). All litters were reduced to $6-8$ pups per mother within 7 days after birth. At 3 weeks of age, litters were weaned to the same diet and water as their dams and transferred to suspended stainless cages. According to the ARVO resolution on Use of Animals in Reseach, the animals were treated. All rats were housed at the Laboratory Animal Center for Biomedical Reseach, Nagasaki University School of 
TABLE 1. Copper deficient diet

\begin{tabular}{lrlr}
\hline Casein & $20.0 \%$ & Choline bitartrate & $0.2 \%$ \\
Cornstarch & $15.0 \%$ & DL-Methionine & $0.3 \%$ \\
Cellulose powder & $5.0 \%$ & Sucrose & $50.0 \%$ \\
Mineral mix & $3.5 \%$ & Corn oil & $5.0 \%$ \\
& & Vitamin mix & $1.0 \%$ \\
\hline & & \multirow{2}{*}{$100.0 \%$} \\
\hline
\end{tabular}

Medicine. Although many copper deficient rats died after 11 weeks of age, the photoreceptor inner segment showed no morphological changes. To study cytochrome oxidase activity in morphologically normal looking mitochondria, 3 copper deficient and 3 normal rats were killed 11 weeks after starting the experiment.

Tissue preparation for electron microscopy

After 11 weeks on a copper deficient diet, the eyes were enucleated under pentobarbital anesthesia, and the serum copper level in blood drawn from the aorta was measured. The eyeball was divided into small pieces and fixed with $2 \%$ glutaraldehyde in $0.1 \mathrm{M}$ phosphate buffer at $4^{\circ} \mathrm{C}$ for $10 \mathrm{~min}$. After being washed with cold $0.1 \mathrm{M}$ phosphate buffer for $90 \mathrm{~min}$, specimens were cut into $80 \mu \mathrm{m}$ thick slices with a vibratome.

With the diaminobenzidine (DAB) method of Seligman et al. (23), slices were preincubated with $0.01 \%$ catalase for $10 \mathrm{~min}$ and incubated in a medium containing $1.0 \mathrm{mg} / \mathrm{ml}$ of $3,3^{\prime}$-diaminobenzidine-tetrahydrochloride salt, $1 \mathrm{mg} / \mathrm{ml}$ of cytochrome c, $0.1 \mathrm{mg} /$ dl of catalase, $7 \%$ sucrose and $0.1 \mathrm{M}$ phosphate buffer at $37^{\circ} \mathrm{C}$ for $60 \mathrm{~min}$. After being washed again in cold

TABle 2. Mineral mix

\begin{tabular}{|c|c|}
\hline $\mathrm{CaHPO}_{4} \cdot 2 \mathrm{H}_{2} \mathrm{O}$ & 60.000 \\
\hline $\mathrm{NaCl}$ & 7.400 \\
\hline $\mathrm{K}_{3} \mathrm{C}_{6} \mathrm{H}_{5} \mathrm{O}_{7} \cdot \mathrm{H}_{2} \mathrm{O}$ & 22.000 \\
\hline $\mathrm{K}_{2} \mathrm{SO}_{4}$ & 5.200 \\
\hline $\mathrm{MgO}$ & 2.400 \\
\hline $\mathrm{MnCO}_{3}$ & 0.350 \\
\hline $\mathrm{FeC}_{6} \mathrm{H}_{5} \mathrm{O}_{7} \cdot 5 \mathrm{H}_{2} \mathrm{O}$ & 0.600 \\
\hline $5 \mathrm{ZnO} \cdot 2 \mathrm{CO}_{2} \cdot 4 \mathrm{H}_{2} \mathrm{O}$ & 0.160 \\
\hline $\mathrm{K}\left(\mathrm{IO}_{3}\right)$ & 0.001 \\
\hline $\mathrm{Na}_{2} \mathrm{SeO}_{3} \cdot 5 \mathrm{H}_{2} \mathrm{O}$ & 0.001 \\
\hline $\mathrm{CrK}\left(\mathrm{SO}_{4}\right)_{2} \cdot 12 \mathrm{H}_{2} \mathrm{O}$ & 0.055 \\
\hline Saccharose & 1.833 \\
\hline Total & 100.000 \\
\hline
\end{tabular}

$0.1 \mathrm{M}$ phosphate buffer for $30 \mathrm{~min}$, they were postfixed with $1 \%$ osmium tetroxide in $0.1 \mathrm{M}$ phosphate buffer. All blocks were dehydrated in a graded ethanol series and propylene oxide, and embedded in Luveak 812. Ultrathin sections were cut and examined in a Hitachi $\mathrm{H}-300$ without staining.

Preparation for light microscopy

After fixation and washing, frozen sections were cut into 5-7 $\mu \mathrm{m}$ thick slices with a cryostat and incubated in the medium containing DAB. Sections were rinsed with $0.1 \mathrm{M}$ phosphate buffer and dehydrated in a series of graded ethanols and embedded in paraffin. Specimens for light microscopy were observed without staining.

For the negative control experiment, specimens were treated with the same medium to which $0.1 \mathrm{M}$ $\mathrm{NaN}_{3}$ was added.

The serum copper level was measured by colorimetry with 2-(2-thiazolylazo)-4-methyl-5-(sulfomethylamino) benzoic acid (18).

Measurement of reactive products

Reactive products resulted from oxidation of DAB deposit on the mitochondrial intermembrane-intracristal space and tended to grow into these spaces.

The area of mitochondrial intermembrane-intracristal space in electron micrographs at the magnification of 70,000 was measured with a computed image analyzer Zeiss IBAS by a point-count method (10.11.24). The area occupied by deposition of reactive product under an adequate threshold was measured with the same method. Tangential sections of mitochondria were eliminated from the measurement. The percentage of the area occupied by reaction product in each mitochondrion was calculated and statistically analyzed.

\section{RESULTS}

\section{Effects of copper deficiency on behavior and growth}

Body weight was not significantly different in the two groups at the beginning of the experiment. In the deficient rats, however, it decreased gradually.

TABLE 3. Serum copper levels $(\mu g / d l)$

\begin{tabular}{l|c|c}
\hline \multirow{2}{*}{ Groups } & \multicolumn{2}{|c}{ Weeks after start of experiment } \\
\cline { 2 - 3 } Copper deficiency & 5 weeks & 11 weeks \\
\hline Control & $\begin{array}{c}10.2 \pm 0.25 \\
(\mathrm{n}=12)\end{array}$ & $\begin{array}{c}20.3 \pm 7.6 \\
(\mathrm{n}=3)\end{array}$ \\
& $\begin{array}{c}89.9 \pm 8.1 \\
(\mathrm{n}=12)\end{array}$ & $\begin{array}{c}102.3 \pm 17.2 \\
(\mathrm{n}=3)\end{array}$ \\
\hline \multicolumn{2}{|c}{$*(\mathrm{P}<0.01)$}
\end{tabular}




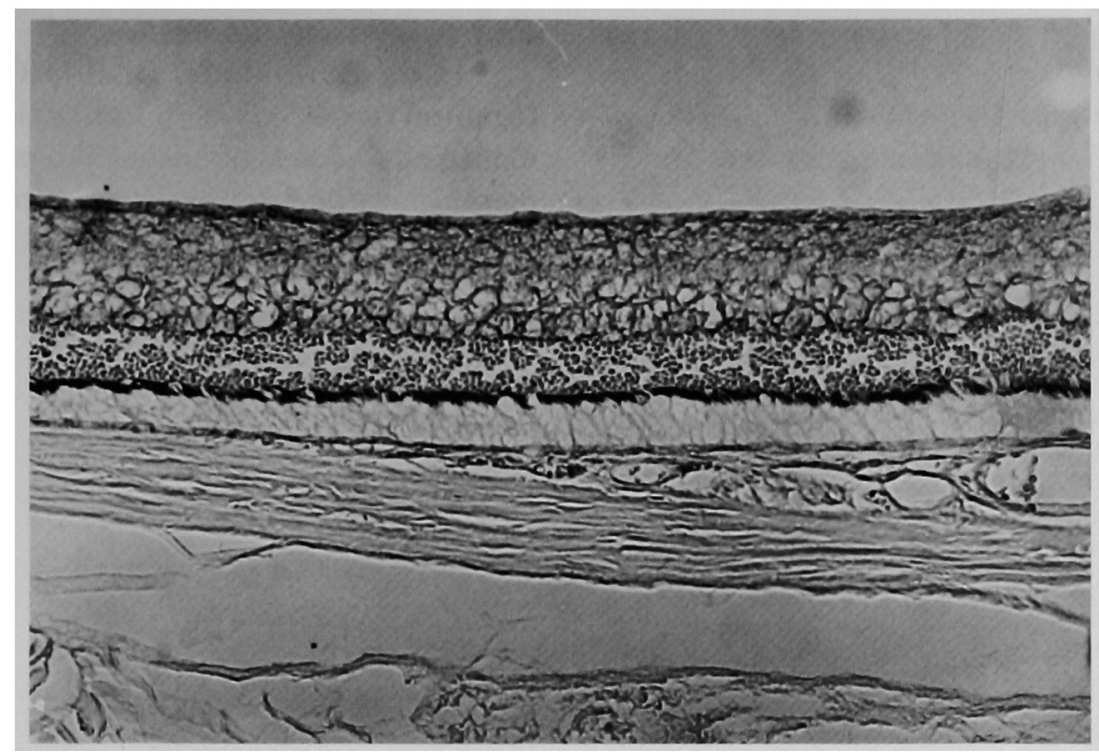

Fig. 1. The nerve fiber layer, ganglion cell layer, inner and outer plexiform layers, pigment epithelial layer and photoreceptor inner segment layer are stained dark brown with DAB reaction products in a control rat. $\quad \times 100$

Within 4 weeks, copper deficient rats exhibited body tremor, inactivity and progressive gait disturbance and some developed total paralysis of their hind limbs. In addition, seizures were observed in a severe case at 5 weeks of age and many copper deficient rats died suddenly after 11 weeks of age.

The serum copper levels in the copper deficient group were significantly lower than in the control group (Table 3).

\section{Light microscopic observation}

The nerve fiber layer, ganglion cell layer, inner and outer plexiform layers, pigment epithelial layer and photoreceptor inner segment layer were stained dark brown in the control group. Especially, the photoreceptor inner segment layer showed an intensely positive reaction (Fig. 1). On the other hand, the deficient group showed light yellow staining in each layer and less stainability. The reaction to

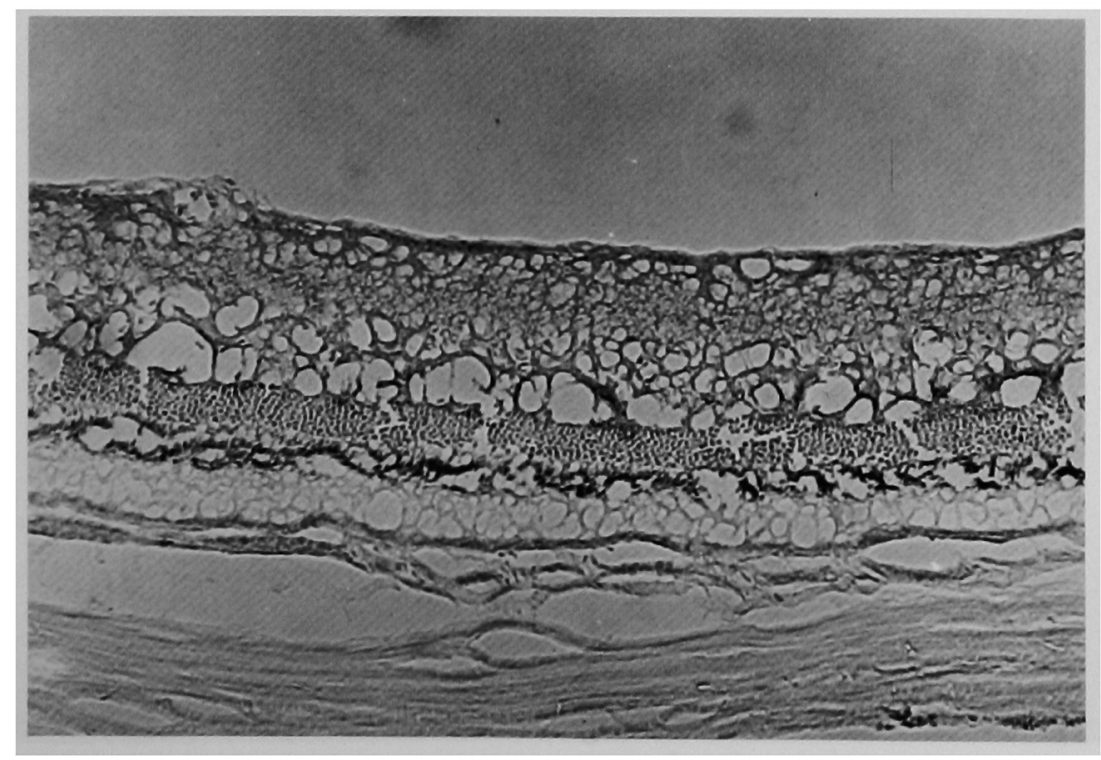

Fic. 2. A copper deficient rat shows light yellow staining in each cell layer of the retina with DAB histochemistry. Photoreceptor inner segments of a copper deficient rat show less staining with DAB. $\times 200$ 
cytochrome oxidase in the photoreceptor inner segments was apparently reduced (Fig. 2). Negative controls incubated with the medium containing $0.1 \mathrm{M}$ $\mathrm{NaN}_{3}$ showed no staining, indicating complete inhibition of reaction (Fig. 3).
Electron microscopic observation

In the control rats, $\mathrm{DAB}-\mathrm{OsO}_{4}$ reaction products (osmium black) resulting from oxidation of DAB were identified as dense nondroplet depositions on the inner membranes and intracristal spaces of the mitochon-



Fig. 3. A negative control retina of a normal rat treated with medium containing $0.1 \mathrm{M} \mathrm{NaN}_{3}$ shows no staining. $\quad \times 200$

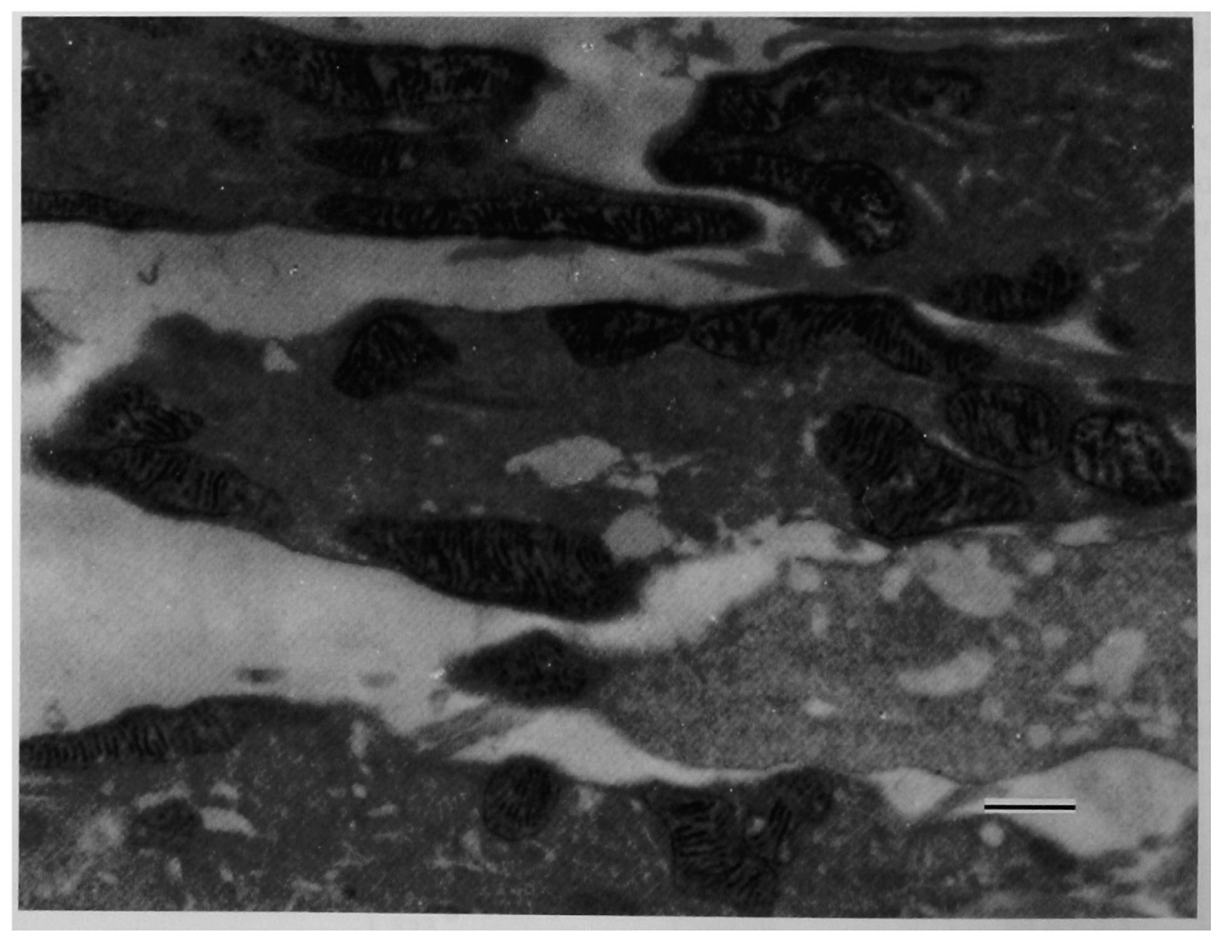

FIG. 4. Electron micrograph of photoreceptor inner segments of a control rat. DAB-OsO 4 reaction products are seen as dense nondroplet depositions on the inner membranes and in the intracristal spaces of mitochondria. $\times 17,000 \quad \mathrm{Bar}=0.5 \mu \mathrm{m}$. 


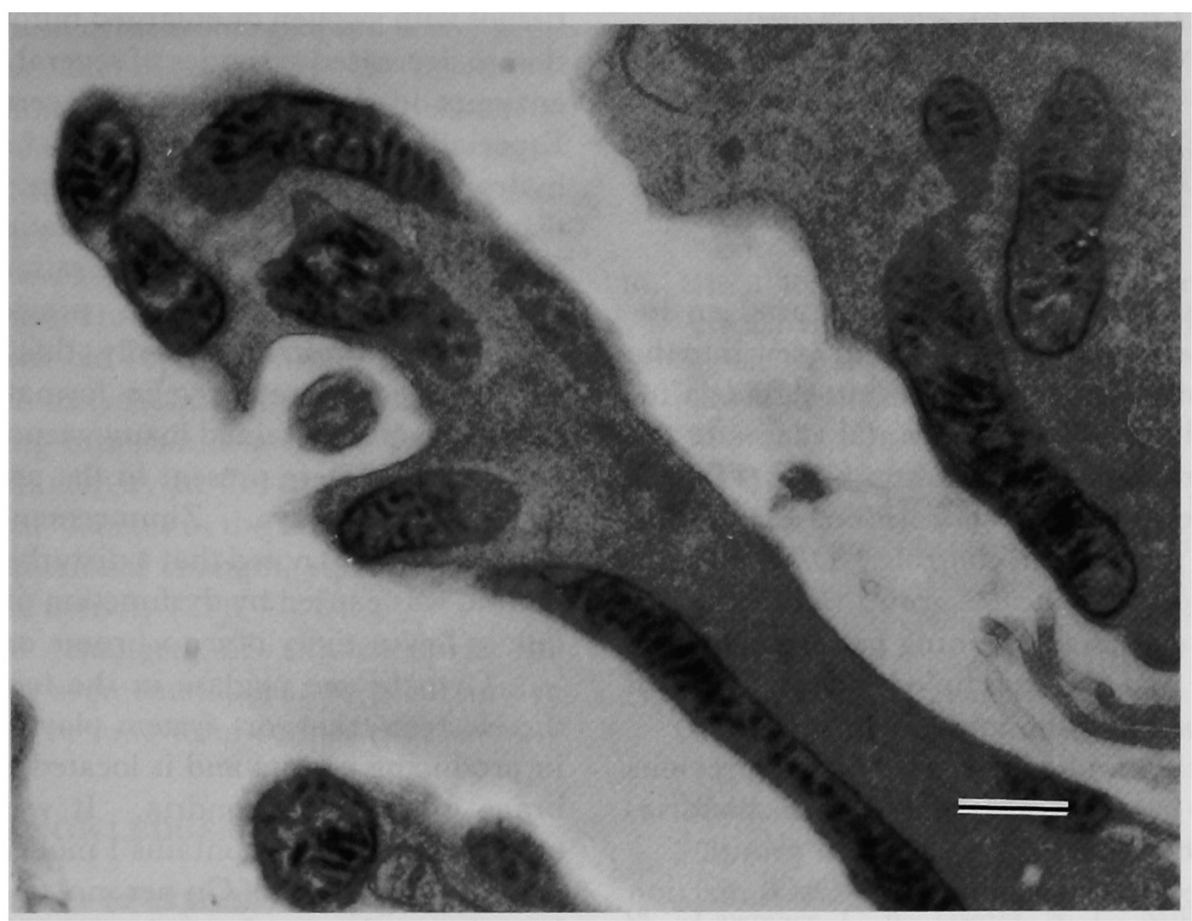

FIg. 5. Electron micrograph of photoreceptor inner segments of a rat fed a copper deficient diet for 11 weeks. Reaction products are located on the inner membranes and in narrow areas of the intracristal spaces of mitochondria. $\quad \times 21,000 \quad B a r=0.5 \mu \mathrm{m}$.

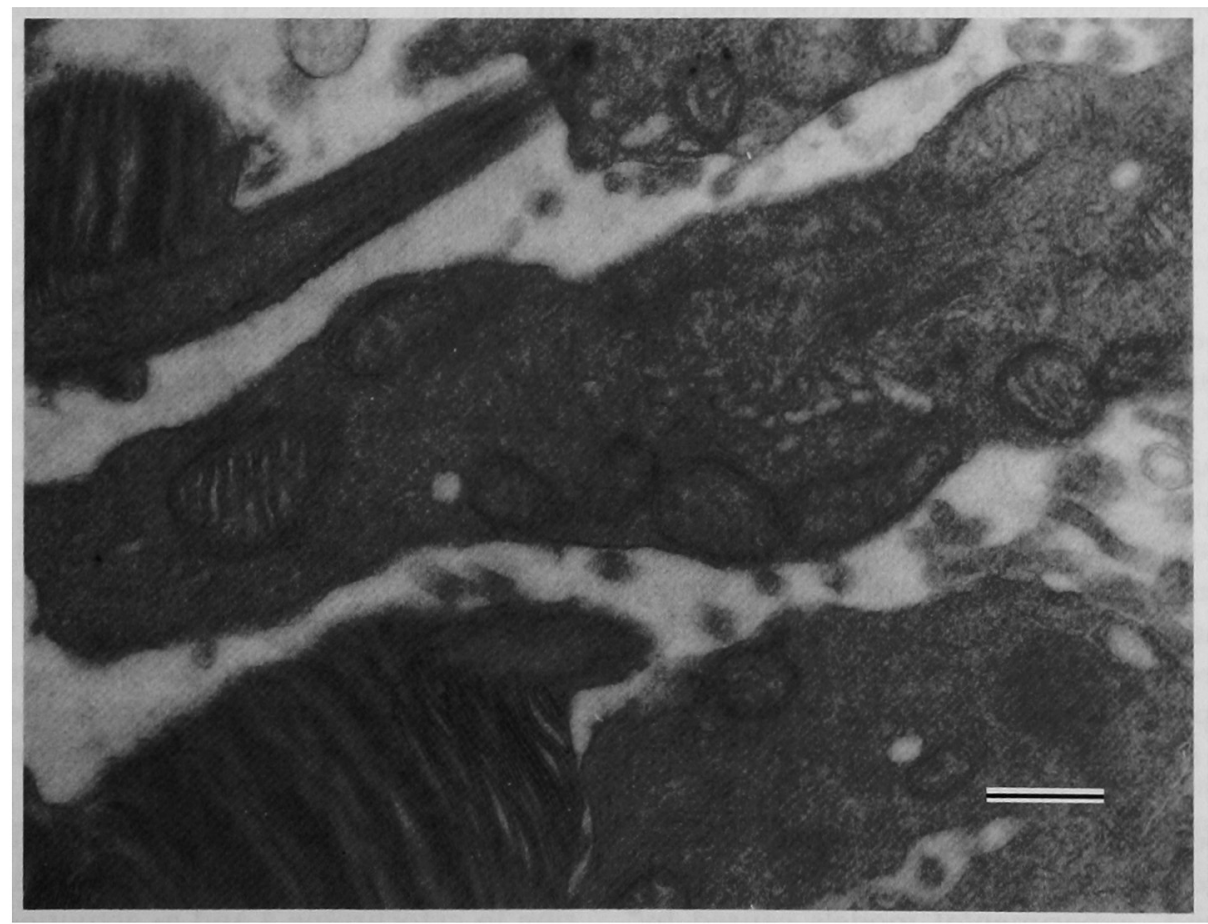

Fig. 6. Electron micrograph of photoreceptor inner segments in a negative control experiment. Mitochondria have no reaction products on the inner membranes or in the intracristal spaces. $\quad \times 24,000 \quad B a r=0.5 \mu \mathrm{m}$. 
TABLE 4. Cytochrome oxidase activity (\% area)

\begin{tabular}{lr}
\hline Control group & $65.2 \pm 8.9 \%^{*}(\mathrm{n}: 30)$ \\
Copper deficient group & $38.0 \pm 18.0 \%^{*}(\mathrm{n}: 30)$ \\
\hline${ }^{*}(\mathrm{p}<0.01)$
\end{tabular}

dria. The deposits of osmium black showed an intense, homogeneous staining pattern and grew into the intermembrane-intracristal space in mitochondria indicating high activity. The intracristal spaces of the mitochondria were filled with osmium black (Fig. 4).

In copper deficient rats, depositions of osmium black were fewer than in the controls. DAB reaction products in the copper deficient group were insignificant and showed a localized staining pattern along the inner membrane and then occupied narrow areas of the intracristal spaces of the mitochondria (Fig. 5).

Morphological findings reported in previous studies, such as swollen or enlarged mitochondria, were not observed in the copper deficient group.

The negative controls had no $\mathrm{DAB}-\mathrm{OsO}_{4}$ reaction products on the inner membranes or intracristal spaces of the mitochondria (Fig. 6).

Quantitative analysis and statistical treatment

The area of reaction products resulting from oxidation of DAB was measured with the image analyzer. The results are shown in Table 4. Each value is a mean $\%$ area occupied by reaction products in intermembrane-intracristal space. The paired $t$ test showed that cytochrome oxidase activity of the copper deficient group is significantly lower than that of the control group.

\section{DISCUSSION}

Menkes' disease was first reported in 1962 as an $\mathrm{X}$-linked recessively inherited neural disorder characterized by progressive defects of the vascular system, kinky hair, bone changes and hypocupremia (17). The pathological changes in Menkes' disease were neural degeneration with marked gliosis, increased numbers of mitochondria and swollen mitochondria $(8,26)$. The basic causes of this neural disorder have been suspected to be defects not only of intercellular transport of copper but also of copper utilization in the cell (13). It has been suggested that abnormalities in copper metabolism reduce the activities of metalloenzymes and are responsible for morphological changes and various clinical features (16). On the other hand, experimental models caused by genetic or dietary copper deficiency in rats, mice and pigs showed spongy, edematous and necrotic neural tissues with swollen or enlarged mitochondria, in addition to decreased activities of several copper dependent enzymes in the cerebellum and cerebrum $(2,6,20)$. Especially metalloenzymes such as dopamine $\beta$ hydroxylase, cytochrome oxidase and superoxide dismutase seem to have close relationships to clinical features and pathological alterations in the copper deficient models. Our previous (4) study demonstrated ultrastructually that in experimental copper deficient rats myelin formation was delayed, swollen axons contained many vacuoles and only a few neurotubules were present in the postlaminar portion in the optic nerve. Zimmerman et al. (28) and Dipaolo et al. (5) noted that a disturbance of myelin formation was caused by dysfunction of oligodendrocytes due to low activity of cytochrome oxidase.

Cytochrome oxidase in the terminal complex of the electron transport system plays an important role in producing energy and is located in the inner membrane of the mitochondria. It was considered that cytochrome oxidase contains $1 \mathrm{~mol}$ each of cytochrome $\mathrm{a}$ and $\mathrm{a}_{3}$ and $2 \mathrm{~mol}$ of $\mathrm{Cu}$ per mol of enzyme. Copper is an integral part of cytochrome oxidase.

Seligman et al. (23) devised a histochemical method to demonstrate cytochrome oxidase activity. The reaction products resulting from the oxidation of $\mathrm{DAB}$ by cytochrome oxidase are present on the inner membranes of mitochondria and tend to grow into the intracristal spaces of mitochondria with strong cytochrome oxidase activity. Because of higher mitochondrial activity in nerve cells, cytochrome oxidase activity is a good metabolic and functional marker for neurons (25).

In the present study less than normal osmium black precipitation was seen on the inner membranes and in the intracristal spaces of mitochondria in copper deficient rats, indicating low cytochrome oxidase activity. On the other hand, osmium black precipitates in the control rats were diffusely located on the inner membranes and completely occupied the intracristal spaces of mitochondria. These findings suggest that the copper deficiency may reduce cytochrome oxidase activity and decrease the function of photoreceptor inner segments.

Biochemical studies have shown that cytochrome oxidase in the mitochondria of copper deficient rats is reduced and that the amount of cytochrome $a$ and $a_{3}$ is $30-40 \%$ of the control value (15). In addition, Prohaska (20) demonstrated enlarged mitochondria in the brains of dietary copper deficient rats with $25 \%$ reduction in cytochrome a and $a_{3}$ activities and $20 \%$ reduction in cytochrome oxidase activity. These findings are in accord with our histochemical findings that cop- 
per deficiency reduces cytochrome oxidase activity.

Morphological alterations such as increased numbers of mitochondria and enlarged mitochondria containing tubulo-vesiculated cristae and dense body formation seen in Menkes' disease, brindled mice and experimental dietary copper deficient rats were not observed in 11-week-old copper deficient rats, although in a previous study (3) swollen mitochondria were seen in 22-week-old copper deficient rats. Since not only the swollen mitochondria but also the majority of normal-looking mitochondria showed very faint cytochrome oxidase activity in the brains of brindled mice, morphological changes in the mitochondria may be secondary to functional changes, such as reduced cytochrome oxidase activity (27).

Morphological changes of mitochondria in photoreceptor inner segments appear to occur under conditions of severe or long-term copper deficiency.

\section{ACKNOWLEDGEMENTS}

The author wishes to express hearty gratitude to Dr. Yoshiaki Hirayama for his advice and Prof. Tsugio Amemiya, Chairman of Department of Ophthalmology, Nagasaki University School of Medicine, for his valuable advice and criticism throughout the present study.

\section{REFERENCES}

1. American Institute of Nutrition.: Report of the American Institute of Nutrition Ad Hoc Committee on Standards for Nutritional Studies. J. Nutr. 107; 140148, 1977.

2. Carlton, W. W. and Kelly, W. A.: Neural lesions in the offspring of female rats fed a copper-deficient diet. $J$. Nutr. 97; 42-52, 1967.

3. Dake, Y. and Amemiya, T.: Retinal changes in copperdeficient rats. Concillium of XXVI Intl. Cong. Ophthalmol., Singapore. 1990.

4. Dake, Y. and Amemiya, T.: Electron microscopic study of the optic nerve in copper deficient rats. Exp. Eye Res. 52; 277-281, 1991.

5. Dipaolo, R. V., Kanfer, J. N. and Newberne, P. M.: Copper deficiency and the central nervous system. Myelination in the rat: Morphological and biochemical studies. J. Neuropathol. Exp. Neurol. 33; 226-236, 1974.

6. Everson, G. J., Tsai, H-C. C. and Wang, T-I.: Copper deficiency in the guinea pig. J. Nutr. 93; 533-540, 1967.

7. Gallagher, C. H. and Reeve, V. E.: Copper deficiency in the rat. Effect on synthesis of phospholipids. Aust. J. Exp. Biol. Med. Sci. 49; 21-31, 1971.

8. Hanaoka, A., Sakai, S., Kurata, M., Mizuno, S., Ikeda, S., Hara, A., Taketomi, T. and Imon, S.: An autopsy case of Menkes' kinky hair disease. Pathological and biochemical study on the central nervous system. No To Hattatsu 18; 223-227, 1986 (in Japanese).

9. Hart, E. B., Steenbock, H., Waddel, J. and Elvehjen, C. A.: Iron in Nutrition VII. Copper as a supplement to iron for hemoglobin building in the rat. J. Biol. Chem. 77; 797-812, 1928.

10. Hirai, K. and Ogawa, K.: Cytochemical quantitation of cytochrome oxidase activity in rat pulmonary alveolar epithelial cells and possible defect in type I cells. J. Electron Microsc. 35; 19-28, 1986.

11. Hirai, K., Ogawa, K., Wang, G. Y. and Ueda, T.: Varied cytochrome oxidase activities of the alveolar Type I, Type II and Type III cells in rat lungs: Quantitative cytochemistry. J. Electron Micross. 38; 449-456, 1989.

12. Hirayama, Y.: Histochemical localization of zinc and copper in rat ocular tissues. Acta Histochem. 89; 107-111, 1990.

13. Hunt, D. M.: Primary defect in copper transport underlies mottled mutants in the mouse. Nature 249; 852-854, 1974.

14. Kitano, S.: Membrane and contractile properties of rat. Vascular tissue in copper-deficient conditions. Circ. Res. 46; 681-689, 1980.

15. Lawrence, C. B., Davies, N. T., Mills, C. F. and Nicol, F.: Studies on the effect of copper deficiency on rat liver mitochondria. I. Changes in mitochondrial composition. Biochim. Biophy. Acta 809; 351-361, 1985.

16. Maehara, M., Ogasawara, N., Mizutani, N., Watanabe, $\mathrm{K}$. and Suzuki, S.: Cytochrome c oxidase deficiency in Menkes' kinky disease. Brain Dev. 5; 533-540, 1983.

17. Menkes', J. H., Alter, M., Steigleder, G. H., Weakley, D. R. and Sung, J. H.: A sex-linked recessive disorder with retardation of growth, peculiar hair, and focal cerebral and cerebellar degeneration. Pediatrics 29; 764779, 1962

18. Morioka, K., Kobayashi, K. and Kanazawa, K.: Evaluation of $\mathrm{Cu}$-shinotest for serum copper measument. Saishin Kensa (Current Labolatory Medicine) 2; 279-283, 1984.

19. Morgan, R. F. and O'Dell, B. L.: Effect of copper deficiency on the concentrations of catecholamines and related enzyme activities in the rat brain J. Neurochem. 28; 207-213, 1977.

20. Prohaska, J. R. and Wells, W. W.: Copper deficiency in the developing rat brain: Evidence for abnormal mitochondria. J. Neurochem. 25; 221-228, 1975.

21. Prohaska, J. R. and Smith, T. L.: Effect of dietary or genetic copper deficiency on brain catecholamines, trace metals and enzymes in mice and rats. J. Nutr. 112; 17061717, 1982

22. Prohaska, J.R.: Changes in tissue growth, concentration of copper, iron, cytochrome oxidase and superoxide dismutase subsequent to dietary or genetic copper deficiency in mice. J. Nutr. 113; 2148-2158, 1983.

23. Seligman, A. M., Karnovsky, M.J., Wasserkrug, H. L. and Hanker, J.S.: Nondroplet ultrastructural demonstration of cytochrome oxidase activity with a polymerizing osmiophilic reagent, diaminobenzidine 
(DAB). J. Cell Biol. 38; 1-14, 1968.

24. Wang, G. Y., Hirai, K. and Odashima, S.: Quantitative cytochemical studies of cytochrome oxidase activity in rat dorsal root ganglion cells. J. Electron Microsc. 39; 231-237, 1990.

25. Wong-Riley, M. T. T. and Kageyama, G. H.: Localization of cytochrome oxidase in the mammalian spinal cord and dorsal root ganglia, with quantitative analysis of ventral horn cells in monkeys. J. Comp. Neurol. 245; 41-61, 1986.

26. Yoshimura, N. and Kudo, H.: Mitochondrial abnor- malities in Menkes' kinky hair disease (MKHD). Electron-microscopic study of the brain from an autopsy case. Acta Neuropathol. 59; 295-303, 1983.

27. Yoshimura, N.: Neuronal degeneration in the brain of the brindled mouse. Histochemical demonstration of decreased cytochrome oxidase activity in the cerebellum and brain stem. Acta Pathol. Jpn. 38; 705-712, 1988.

28. Zimmerman, A. W., Matthieu, J-M., Quarles, R. H., Brady, R. O. and Hsu, J. M.: Hypomyelination in copper-deficient rats. Prenatal and postnatal copper replacement. Arch. Neurol. 33; 111-119, 1976. 